\title{
Broken trust drives native health disparities
}

$\mathrm{D}$ istrust between Aboriginal Canadians and the medical establishment remains a major driver of health inequities, said presenters at Canada's first Indigenous Health Conference.

Just as Aboriginal people seldom interact with the justice system unless "they're dragged in" by criminal or child welfare proceedings, they also avoid the medical system, which has historically been a tool of their oppressors, said keynote speaker Justice Murray Sinclair, chair of the Truth and Reconciliation Commission of Canada.

"The most significant point of contact between indigenous people and the medical system is often the emergency ward," he noted. "At that point in time they have no choice but to engage."

And they have good reason to be wary; Sinclair and other presenters at the Toronto conference held Nov. 20 and 21 cited a litany of abuse, coercion and forced separation of Aboriginal families in which health professionals and systems were party - from experimentation on malnourished children in residential schools, and the spiriting away of patients with tuberculosis on a specially designed Coast Guard ship, to a recent legal battle to force chemotherapy on an Ontario girl.

These experiences can't be separated from the ongoing health disparities faced by Aboriginal Canadians, and the onus is on the health system to mend that broken trust, urged Sinclair.

"Western medical professionals have to make more effort to learn about this experience because it's front and centre in the lives of all indigenous people," he said. "The effectiveness of treatment is going to be hampered if they only treat the illness [instead of the whole person]."

\section{Forced chemo case decried}

The recent battle in Ontario between a hospital and child welfare services over

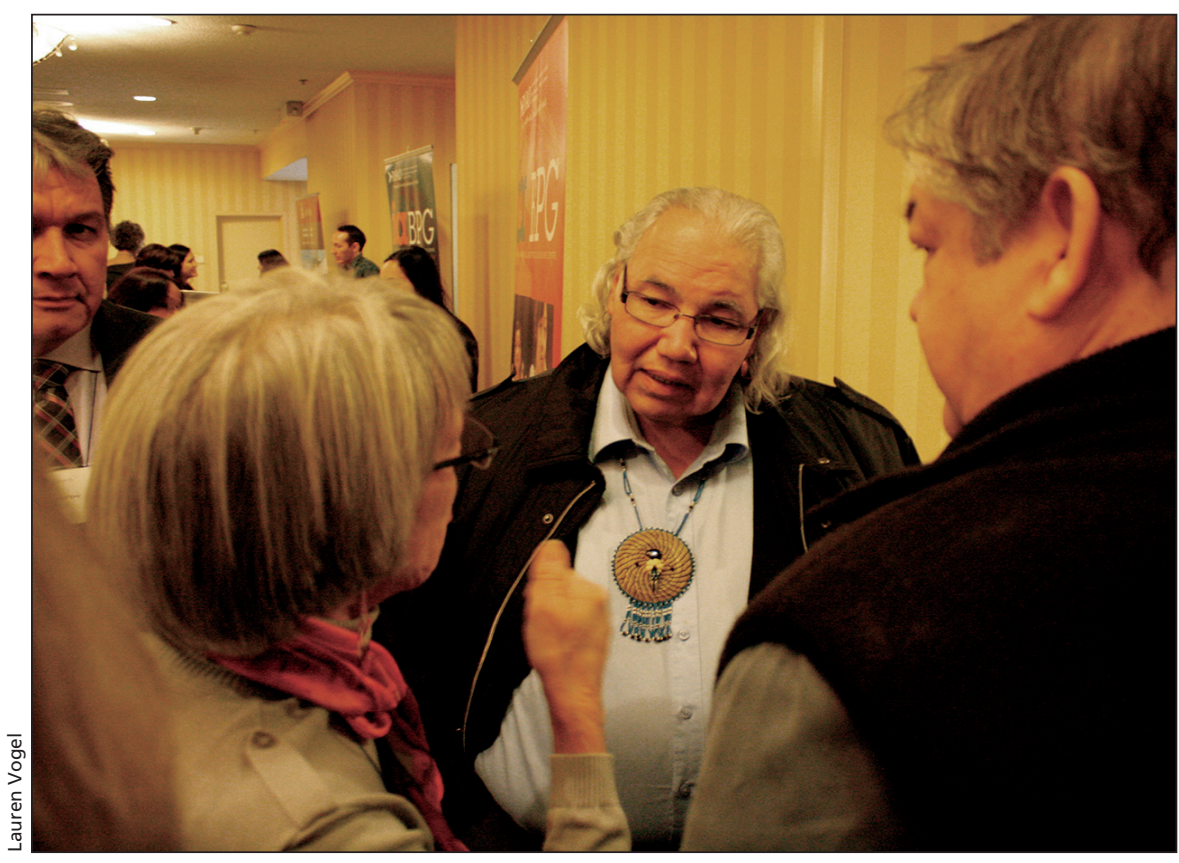

Refusing to embrace Aboriginal healing practices only alienates an already vulnerable population, Justice Murray Sinclair (centre) said at Canada's first Indigenous Health Conference.

treatment of an 11-year-old Aboriginal girl with leukemia is one such example, argued Sinclair. McMaster Children's Hospital in Hamilton, Ontario, sought to have the child taken from her family. The family pulled her out of chemotherapy to seek other treatments herbal supplements and diet changes from a Florida company. An Ontario judge ruled Nov. 21 that the family had a constitutional right to opt for what he deemed traditional medicine.

Discussions at the conference skirted examination of the effectiveness of such therapies in the case of cancer, beyond their impact on overall well-being and importance to "identity reclamation."

According to Sinclair, "that's the fallacy of the Western model; there's an inherent belief that the chemical approach is right."

$\mathrm{He}$ also dismissed concerns that companies flogging such therapies as cancer cures may be preying on First Nations communities that feel they have been burned by mainstream medi- cine. "There is such an incredible sense of superiority that the Western medical community brings to this discussion that they refuse to consider the possibility that alternative medicine can provide part of the solution."

\section{Success in BC}

Presenters also called on governments to share more of the responsibility for indigenous health care with the communities in question, citing British Columbia's First Nations Health Authority (FNHA) as a possible model.

The First Nations-led health authority is another first for Canada. Last year it assumed province-wide control over First Nations health services previously managed and delivered by Health Canada. Since that time, the authority has extended telehealth services to 38 communities and reduced service times for delivery of health benefits. There's also early evidence of reductions in infant mortality and youth suicide, said FNHA Chief Medical Officer Dr. Evan Adams. 
"Our health indicators say we are making a difference."

Part of this difference is a more holistic approach to care, he explained. "People are very clear they don't want their newly reformed health system to be a carbon copy of the Western health care system."
Although the FNHA doesn't provide alternative therapies, "we have First Nations physicians who work in these areas ... and we encourage the use of cultural workers, singing, prayer and ceremony in the hospitals," said Adams.

Officials are also looking to expand the role of traditional healers under the new system. "We're working out a couple of things like certification ... and we've been asked to consider paying traditional healers the way we pay other health workers and we're very open to that." — Lauren Vogel, CMAJ

CMAJ 2015. DOI:10.1503/cmaj.109-4950 